\title{
The Potential Impact of Mobile Phone Use on Trends in Brain and CNS Tumors
}

\author{
Örjan Hallberg ${ }^{1 *}$ and L Lloyd Morgan ${ }^{2}$
}

${ }^{1}$ Hallberg Independent Research, Brattforsgatan 3, 12350 Farsta, Sweden

${ }^{2}$ Environmental Health Trust, 2022 Francisco Street, Berkeley, CA 94709, USA

\begin{abstract}
Background: Case-control studies have reported an increased risk of brain tumors after 10 or more years of cell phone use.

Objective: To model brain cancer trends by extracting characteristic risk functions from reported data and to use these for projecting future trends accounting for possible influences from mobile phone use.

Methods: Normally occurring DNA brain cell damage during one year was assumed to be associated with a cancer risk function that is increasing over time but balanced by a DNA repair function reducing the amount of potential carcinogen damages over time. By model parameter adjustments of risk functions, calculated age-adjusted rates were made to best fit the reported data. The model also accounted for increasing levels of initial DNA brain damage or decreasing repair efficiency, caused by cell phone use.

Results: DNA brain cell damage has an average latency time of over 30 years before increased brain cancer rates would be expected. Mobile phone use may lead to a reduced DNA repair function resulting in about a 2-fold increase in brain cancer incidence, or with an increasing rate of initial DNA brain damage from mobile phone use a 25 -fold increase in brain cancer incidence may result.
\end{abstract}

Keywords: Mobile phones; Brain tumors; Brain cancer; DNA repair; DNA damage; Latency time

\section{Introduction}

\section{Background}

All case-control studies which covered $>10$ years of use have reported an increased risk of brain tumors from the use of mobile phones [1-3]. Mobile phone radiation exposure limits are based on thermal heating of the body and the brain [4]. Many research studies have identified biological effects far below the thermally based exposure limits, such as increased permeability of the blood-brain barrier in the head [5], deleterious effects on sperm [6-8], double strand breaks in DNA [9], and stress gene activation indicating an exposure to a toxin, [10]. Other studies have pointed at an increasing risk of acoustic neuroma and brain cancer after several years of cell phone use [11-12], and especially so in more sparsely populated regions where the output power from cell phones generally is increased compared with that in a city region in close contact to base stations, [13-14]. Additional studies have reported increased risk of salivary gland tumors and eye cancer [15-16].

It is, however, well known for many cancer types, including brain cancer that it takes many years to develop initial cell damage or a cluster of cell damage sufficient to diagnose "benign" or malignant cancers in the brain. Thus, we are facing a painful period of following the cancer statistics to see, if and when, this latency will eventually release the ugly face of a brain cancer pandemic.

\section{Object}

The main object of this study was to develop a general macro model to estimate brain cancer incidence over calendar time. A second object was to use this general model to estimate the future outcome of any changes in DNA cell repair efficiency or in annual DNA cell damage rates. The third object was to use the model to analyze brain cancer statistics since the mid $20^{\text {th }}$ century to actually quantify the brain cancer risk functions and associated latency times. This information could allow Public Health to be in a better position to forecast a potential brain cancer pandemic resulting from use of mobile phones. Such information would allow Public Health agencies to perform contingency planning prior to the onset of a potential pandemic; for example, how many neurosurgeons would be required in the event of a brain cancer pandemic.

\section{Methods}

In an earlier study [17] it was shown that melanoma incidence could be modeled by the combination of two log-normal statistical distributions. One function described the increasing risk of melanoma after one year of normally acquired skin damage from UV exposure. The other function described the rate and probability that such damage is repaired over time, such that the total risk in a natural environment could be predicted.

The only "known" cause of brain cancer is ionizing radiation. There is reason to believe that DNA cell damage occurs in the brain continuously and that such damage normally is taken care of by the DNA repair system. If the rate of DNA brain damage is increased

*Corresponding author: Örjan Hallberg, Hallberg Independent Research Brattforsgatan 3, 12350 Farsta, Sweden, Tel: +46-8-605 4998; E-mail: oerjan. hallberg@swipnet.se

Received July 29, 2011; Accepted December 12, 2011; Published December 20, 2011

Citation: Hallberg Ö, Morgan LL (2011) The Potential Impact of Mobile Phone Use on Trends in Brain and CNS Tumors. J Neurol Neurophysiol S5. doi:10.4172/21559562.S5-003

Copyright: @ 2011 Hallberg Ö, et al. This is an open-access article distributed under the terms of the Creative Commons Attribution License, which permits unrestricted use, distribution, and reproduction in any medium, provided the original author and source are credited. 
Citation: Hallberg Ö, Morgan LL (2011) The Potential Impact of Mobile Phone Use on Trends in Brain and CNS Tumors. J Neurol Neurophysiol S5. doi:10.4172/2155-9562.S5-003

or the efficiency of DNA repair is decreased, then the brain cancer incidence will inevitably increase. The two functions used to describe the increasing risk of cancer and decreasing amount of still active DNA damage over time are the log-normal distributions determined by the two parameters described below.

\section{Hypotheses}

The incidence of brain cancer has generally been slowly increasing since beginning of the $20^{\text {th }}$ century, and has in several countries stabilized in recent years. Our first hypothesis is that this increase was caused by environmental changes that may reduce the efficiency of the DNA repair system in the brain. If this is the case we should expect to see a stabilization of the incidence, first in the younger age groups and later successively by older age groups. This is because a young age cohort, say 25 years, would have spent their whole life in the new environment after 1975 if the environmental change took place in 1950 e.g. An older cohort, say 50 years, would have to wait until 2000 before all 50 year old people have spent their whole life in the new environment, etc. This reduced DNA repair efficiency analysis can be used to define the characteristic function of the increased risk of brain cancer. Our second hypothesis is that the same characteristic function can be used in case new environmental changes start causing additional brain damage on top of the ordinary, 'natural' ones.

\section{Definitions}

For every year during a person's life a certain amount of brain DNA damage occurs, either "naturally", or due to external environmental influence. A 'life matrix' is defined (Table 1) where the partial cancer risks originating from each year of a person's life are added vertically together. For example, each birth cohort from 1880 to 1980 is attributed with its own life matrix thus making it possible to calculate the age-specific incidence rates over calendar time. From these sets of calculated data the age-adjusted incidence rates over calendar time are calculated.

The annual amount of DNA brain damage is associated with a risk of developing brain cancer, described by a standard log-normal life distribution, $\mathrm{C}(\mathrm{t})$. This brain cancer risk distribution, $\mathrm{C}(\mathrm{t})$, is characterized by only two parameters, (1) the dispersion, d, and (2) the median time, $\mathrm{T}_{\mathrm{m}}$, here equated to the time to convert $0.1 \%$ of the initial DNA damage dose into a brain tumour, $\mathrm{T}_{\mathrm{m}(0.1 \%)}$. The median time is calculated as $\mathrm{T}_{\mathrm{m}}=\mathrm{T}_{\mathrm{m}(0.1 \%)}{ }^{*} \exp \left(3,09024^{*} \ln (10)^{*} \mathrm{~d}\right)$. The dispersion $\mathrm{d}$ is the number of time decades between the inflexion point and the median value, just as the standard deviation is defined as the time difference between the inflexion point and the median value of a normal distribution. The figure 3.0924 is the number of standard deviations between median value and time to $0.1 \%$ in a normal distribution. The damage repair function, $\mathrm{R}(\mathrm{t})$, will reduce the active damage over time so that the total cancer risk is $\mathrm{F}(\mathrm{t})=(1-\mathrm{R}(\mathrm{t}))^{*} \mathrm{C}(\mathrm{t})$. During one year $\mathrm{t}$ the risk will be $\mathrm{F}_{\mathrm{x}}=\mathrm{F}(\mathrm{t})-\mathrm{F}(\mathrm{t}-1)$ as shown in each row in Table 1 . The total cancer risk during one year for a person is then the vertical sum of all those partial risks from damages created during each year of a person's life. As an example, the total cancer risk, $\mathrm{C}$, for year 2 is: $\mathrm{N}_{1} \mathrm{~F}_{2}+\mathrm{N}_{2} \mathrm{~F}_{1}$, for year 3: $\mathrm{N}_{1} \mathrm{~F}_{3}+\mathrm{N}_{2} \mathrm{~F}_{2}+\mathrm{N}_{3} \mathrm{~F}_{1}$ and so on. In a natural state all $\mathrm{N}_{\mathrm{i}}$ is given the same value, while when related to annual mobile phone use time held to the ear, where $\mathrm{N}_{\mathrm{i}}$, also accounts for the extra amount of DNA damage in the brain.

The cancer probability was defined by two parameters $\mathrm{d}$ and $\mathrm{T}_{\mathrm{m}(0.1 \%)}$ as shown in Table 2. Figure 1 gives as example the remaining fraction of initial damages as a function of time in years, for a "natural" and for a disturbed DNA. For example, in a natural state $50 \%$ of the damages acquired during one year would have been repaired within 18 years, while in the disturbed state it would take 36 years. For the calculation of these graphs a dispersion of $\mathrm{d}=0.33$ was used for both cases while

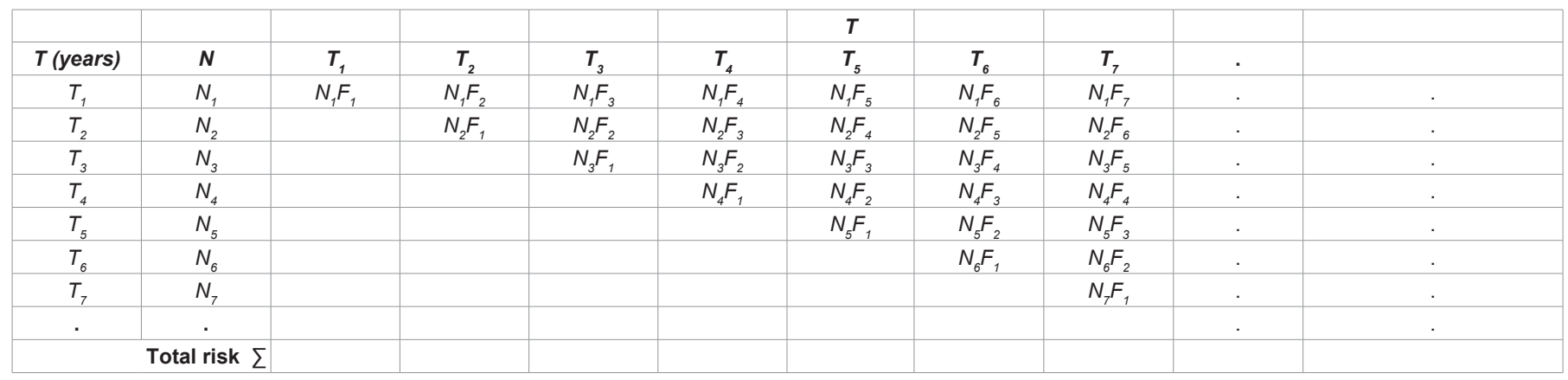

$N_{i}$ is a DNA damage factor; $F_{i}$ is a cancer risk factor

Table 1: Life Matrix. The principle construction of the life matrix is where the risk function, $\mathrm{F}^{\mathrm{i}}$, is multiplied by the brain DNA damage factor, $\mathrm{N}_{\mathrm{i}}$, and then summed vertically for each calendar year.

\begin{tabular}{|l|c|c|}
\hline \multicolumn{1}{|c|}{ Country } & Dispersion, d (decades) & Time to 0.1 \%, $T_{\text {m(0.1\%) }}($ years) \\
\hline Sweden & 0.33 & 28.99 \\
\hline Norway & 0.33 & 28.84 \\
\hline Finland & 0.33 & 29.26 \\
\hline Denmark & 0.33 & 28.20 \\
\hline Sweden, VG & 0.33 & 28.15 \\
\hline USA & 0.33 & 32.25 \\
\hline
\end{tabular}

Table 2: Optimum parameters used for best fit to reported age-standardized data for various available yearly ranges. 
Citation: Hallberg Ö, Morgan LL (2011) The Potential Impact of Mobile Phone Use on Trends in Brain and CNS Tumors. J Neurol Neurophysiol S5. doi:10.4172/2155-9562.S5-003

the $\mathrm{T}_{\mathrm{m}(0.1 \%)}$ was 2 years for the natural case and 4 years for the disturbed case, Figure 1.

The model application was designed to account for three different possibilities. One option was to calculate the incidence if the use of mobile phones simply stopped the repair process so that the amount of unrepaired DNA damage would stay constant over time, and total damage would accumulate in time. The second option was to calculate the effect if mobile phone use actually created increased DNA damage. The third option was to predict future rates if mobile phone use did not have any effect on DNA damage.

Using this general model structure it is possible to test various hypotheses. In order to determine the basic statistical parameters of the cancer risk function $\mathrm{C}(\mathrm{t})$, these 3 hypotheses were adjusted to make the calculated age-adjusted rates best fit reported rates. Even if calculated age-adjusted incidence rates fit well to the reported incidence data, calculated age-specific incidence rates might not fit well to the reported data. But if it does, it is a strong indication that the model is realistic.

In such a best fit procedure one may regard the dispersion as a parameter that is characteristic for the disease (here brain cancer) while the time to convert $0.1 \%$ of the DNA damage into a brain tumor, $\mathrm{T}_{\mathrm{m}(0.1 \%)}$, is a characteristic of the environmental stress. Thus, when performing the best fit procedure on reported data from different countries it should be expected that the same dispersion could be used for all countries while some level of fine-tuning of the characteristic time to convert $0.1 \%$ of the DNA damage into a brain tumor may be required for each country. If, for example, the general level of household electrification since the beginning of the $20^{\text {th }}$ century has evolved differently in different countries, then it would be reasonable to expect somewhat different time dependencies of brain cancer in different countries $[18,19]$.

Ninety-one per cent of brain cancers are cancers of the glial cells, collectively known as gliomas [20]. Most cancer registries do not report non-malignant brain tumors, but only report malignant brain tumors also known as brain cancer. As the vast majority of brain cancers are glial cell cancers, it is reasonable to assume very similar effects on glial cell DNA.

Data from the Nordic countries and from the USA were used to extract basic parameters. After finding the optimum dispersion and time to convert $0.1 \%$ of the original DNA damage into brain cancer from the Norwegian data, the same dispersion was used for all countries and only the time to convert $0.1 \%$ of the DNA damage into a brain tumor was varied to get best fit to data from each individual country. Norway was chosen as the base due to a good set of data and because the age-specific trends did fit well to reported data without any extra fine tuning of the parameters.

\section{Results}

The analysis of brain cancer statistics since mid $20^{\text {th }}$ century in several countries gives a clear picture of a disease having a long latency time, an average of over 30 years which is consistent with another study [21]. We also found that some countries, e.g., Norway, Denmark and parts of Sweden recently (1997-2007) have seen increasing age-adjusted incidence rates for brain cancer (see Figure 2 for Norway), possibly levelling off in 2008 (Table 3). This increase is also seen for age-specific incidence rates, both among younger and older age cohorts. It is not possible today to determine if that increase is caused by an increased

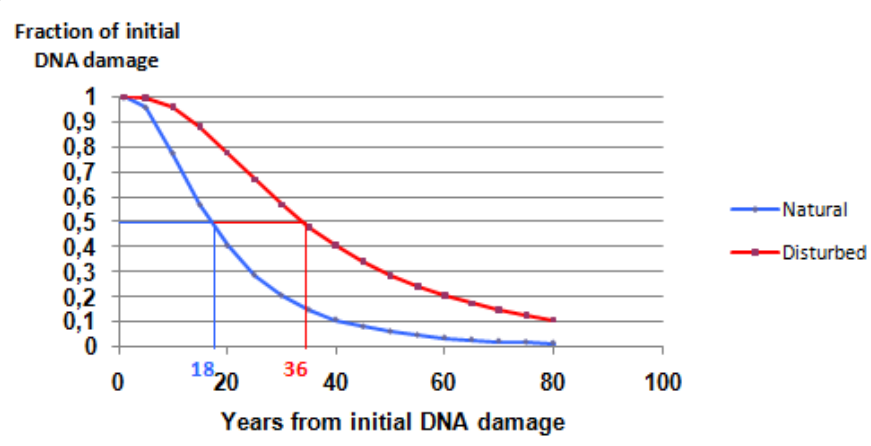

Figure 1: Fraction of initial DNA damage from "natural" and disturbed environmental effects a function of years from the initial DNA damage. The repair functions used to describe the natural efficiency (before e.g. 1940) and a less efficient repair function after 1940.

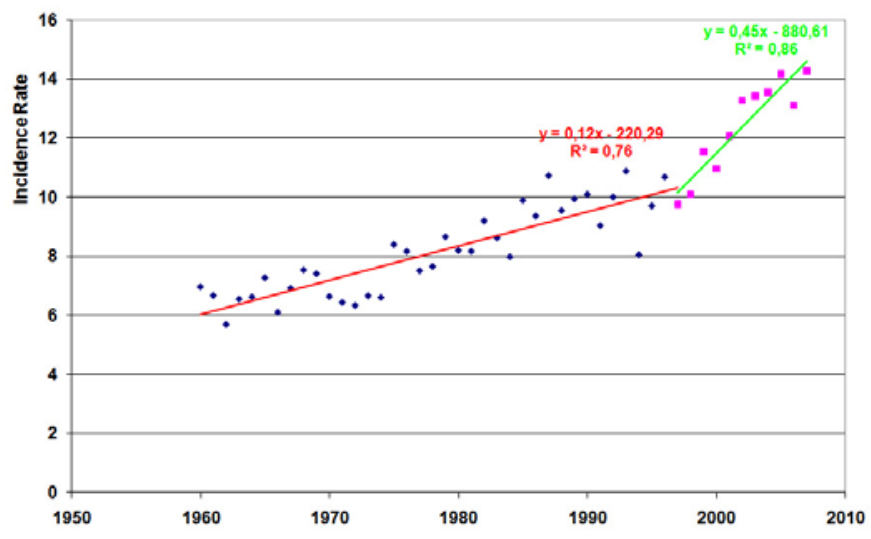

Figure 2: Norwegian age-adjusted brain tumor incidence rates, 1960-2007.

rate of initial DNA brain damage, or if it is caused by a further reduced DNA damage repair rate in the brain. The model suggests, however, that the age-adjusted rates may increase by a factor of 1.9 by year 2040 as compared to 2007 if a reduced repair rate is the cause, or by a factor of 6.4 by year 2040 as compared to 2007, and increasing to 25 or more in later decades if increased brain DNA damage is the main cause. See Figure 3.

The same dispersion as for Norway was used for all countries, while the time to $0.1 \%$ had to be varied slightly to fit reported agestandardized rates. For all countries the repair rate was characterized by a dispersion of 0.33 and a time to $0.1 \%$ of 2 years before 1950 and 4 years after 1950 (Figure 1). Note that these short times of 2 and 4 years relate to the repair function while the longer times of 28-32 years relate to the cancer risk function as shown in Table 2.

Figure 3 shows the reported age-adjusted rates in Norway and the calculated age-adjusted rates if there is no effect from cell phone use. As can be seen, the calculated age-adjusted rates would level off after a purported decrease in the DNA brain repair rate that occurred after 1950 had been affected by all age groups. Figure 2 shows two linear trend lines: from 1960-1997, and from 1997-2007

In order to account for the increasing age-adjusted rates in Norway after about 1997 we tested two options. Figure 4A compares the calculated results if increasing use of mobile phones reduces DNA 
Citation: Hallberg Ö, Morgan LL (2011) The Potential Impact of Mobile Phone Use on Trends in Brain and CNS Tumors. J Neurol Neurophysiol S5. doi:10.4172/2155-9562.S5-003

Page 4 of 8

repair rates with reported results. Figure $4 \mathrm{~B}$ compares the reported results to the calculated results if mobile phone use increases DNA damage. It is still too early to conclude which one of the two options best fit reported data.

Figure 5 shows as an example the age-specific reported rates in Norway for the age groups 65-69 (67) and 30-34 (32) years compared to calculated results due to increased DNA damage.

It was also possible to calculate the number of future brain cancer

\begin{tabular}{|c|c|c|c|c|c|}
\hline Year & Denmark & Finland & Norway & Sweden & USA \\
\hline 1943 & 5,63 & & & & \\
\hline 1944 & 5,23 & & & & \\
\hline 1945 & 5,12 & & & & \\
\hline 1946 & 5,56 & & & & \\
\hline 1947 & 5,95 & & & & \\
\hline 1948 & 5,97 & & & & \\
\hline 1949 & 5,58 & & & & \\
\hline 1950 & 5,34 & & & & \\
\hline 1951 & 5,56 & & & & \\
\hline 1952 & 5,74 & & & & \\
\hline 1953 & 5,54 & 4,21 & 5,33 & & \\
\hline 1954 & 5,59 & 4,00 & 5,97 & & \\
\hline 1955 & 6,21 & 3,99 & 6,42 & & \\
\hline 1956 & 6,76 & 5,05 & 5,92 & & \\
\hline 1957 & 6,72 & 4,32 & 6,64 & & \\
\hline 1958 & 6,78 & 4,18 & 6,36 & & \\
\hline 1959 & 7,25 & 3,62 & 6,51 & & \\
\hline 1960 & 7,59 & 5,11 & 6,97 & 7,46 & \\
\hline 1961 & 7,50 & 4,86 & 6,67 & 7,00 & \\
\hline 1962 & 7,81 & 4,71 & 5,70 & 7,37 & \\
\hline 1963 & 7,40 & 5,26 & 6,55 & 7,26 & \\
\hline 1964 & 7,50 & 5,44 & 6,63 & 8,73 & \\
\hline 1965 & 7,20 & 5,13 & 7,27 & 7,98 & \\
\hline 1966 & 6,78 & 5,58 & 6,11 & 7,79 & \\
\hline 1967 & 8,07 & 5,78 & 6,92 & 8,74 & \\
\hline 1968 & 8,21 & 5,82 & 7,53 & 8,60 & \\
\hline 1969 & 7,04 & 6,42 & 7,40 & 9,12 & \\
\hline 1970 & 7,79 & 5,86 & 6,64 & 8,68 & \\
\hline 1971 & 7,60 & 6,73 & 6,44 & 9,12 & \\
\hline 1972 & 8,20 & 6,23 & 6,34 & 8,67 & \\
\hline 1973 & 7,68 & 6,31 & 6,66 & 8,18 & \\
\hline 1974 & 8,11 & 6,61 & 6,61 & 7,92 & \\
\hline 1975 & 9,17 & 6,98 & 8,39 & 8,22 & 5,85 \\
\hline 1976 & 9,37 & 6,66 & 8,16 & 8,83 & 5,82 \\
\hline 1977 & 8,13 & 6,26 & 7,52 & 8,20 & 6,17 \\
\hline 1978 & 10,06 & 7,96 & 7,65 & 9,29 & 5,76 \\
\hline 1979 & 8,56 & 8,32 & 8,65 & 8,78 & 6,12 \\
\hline
\end{tabular}

\begin{tabular}{|c|c|c|c|c|c|}
\hline 1980 & 9,77 & 9,64 & 8,20 & 9,07 & 6,30 \\
\hline 1981 & 9,30 & 8,12 & 8,18 & 8,48 & 6,50 \\
\hline 1982 & 8,88 & 8,96 & 9,20 & 9,61 & 6,43 \\
\hline 1983 & 10,21 & 8,31 & 8,62 & 9,77 & 6,31 \\
\hline 1984 & 9,50 & 8,22 & 8,01 & 10,82 & 6,12 \\
\hline 1985 & 9,73 & 9,26 & 9,89 & 10,41 & 6,94 \\
\hline 1986 & 10,44 & 9,56 & 9,37 & 10,80 & 6,84 \\
\hline 1987 & 10,45 & 9,28 & 10,71 & 10,80 & 6,99 \\
\hline 1988 & 10,73 & 9,15 & 9,57 & 10,59 & 6,83 \\
\hline 1989 & 11,16 & 8,84 & 9,93 & 10,75 & 6,86 \\
\hline 1990 & 10,96 & 9,28 & 10,11 & 10,41 & 7,05 \\
\hline 1991 & 11,25 & 9,47 & 9,04 & 9,59 & 6,96 \\
\hline 1992 & 11,03 & 10,24 & 10,02 & 10,64 & 6,98 \\
\hline 1993 & 11,09 & 9,75 & 10,85 & 10,56 & 6,78 \\
\hline 1994 & 11,53 & 9,39 & 8,01 & 10,21 & 6,61 \\
\hline 1995 & 11,95 & 9,68 & 9,68 & 10,79 & 6,49 \\
\hline 1996 & 12,56 & 10,13 & 10,73 & 10,01 & 6,68 \\
\hline 1997 & 12,12 & 10,30 & 9,78 & 11,22 & 6,77 \\
\hline 1998 & 13,79 & 9,71 & 10,04 & 10,95 & 6,64 \\
\hline 1999 & 12,15 & 9,83 & 11,49 & 10,31 & 6,95 \\
\hline 2000 & 13,11 & 9,56 & 10,99 & 9,88 & 6,83 \\
\hline 2001 & 12,02 & 10,64 & 11,99 & 9,58 & 6,64 \\
\hline 2002 & 12,22 & 10,80 & 13,24 & 10,36 & 6,76 \\
\hline 2003 & 11,10 & 11,42 & 13,42 & 10,10 & 6,68 \\
\hline 2004 & 13,22 & 10,26 & 13,49 & 9,77 & 6,82 \\
\hline 2005 & 13,55 & 10,82 & 14,20 & 10,67 & 6,77 \\
\hline 2006 & 13,73 & 11,20 & 13,32 & 10,43 & 6,38 \\
\hline 2007 & 14,22 & 10,75 & 14,88 & 9,68 & 6,63 \\
\hline 2008 & 14,89 & 9,79 & 12,66 & 8,78 & \\
\hline 2009 & 14,01 & & & & \\
\hline
\end{tabular}

Table 3: Reported Age-standardized rates of Brain and CNS tumors in the Nordic countries and of Brain cancer in the USA. All rates are brain cancer per 100,000 person years for men and women together.

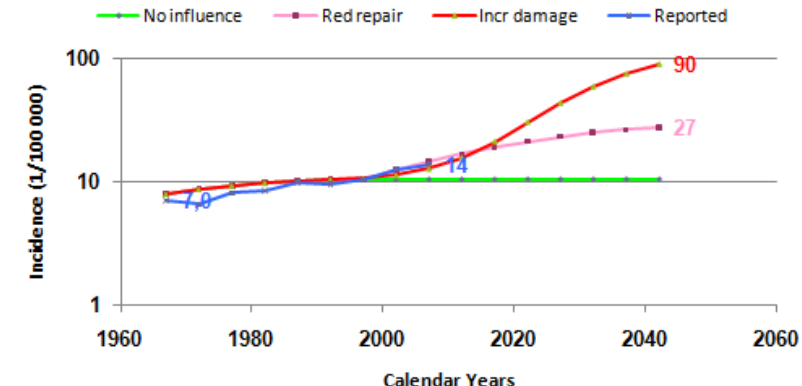

Figure 3: Norwegian brain tumor age-adjusted incidence rates per 100,000 person-year by calendar year for reported data with 3 results from mobile phone use: 1) increased DNA damage, 2) no DNA repair, and 3) has no affect. 
Citation: Hallberg Ö, Morgan LL (2011) The Potential Impact of Mobile Phone Use on Trends in Brain and CNS Tumors. J Neurol Neurophysiol S5. doi:10.4172/2155-9562.S5-003

cases in Norway for the different options. Figure 5 shows the projections for increased DNA damage rate due to mobile phone use.

Table 2 gives the parameters used for the different countries. A reduced repair rate was assumed to have started from 1950 and onwards to explain the increasing rates among elderly and stable rates among younger cohorts after 1970 (Figure 5).

Age adjusted rates tend to vary in different parts of Sweden. The rates for the whole of Sweden seem quite stable or even decreasing over time since the mid 80's (Figure 6). In Denmark the incidence has been increasing in a stable pattern for many years, Figure 7, as is also true in Finland, Figure 8.

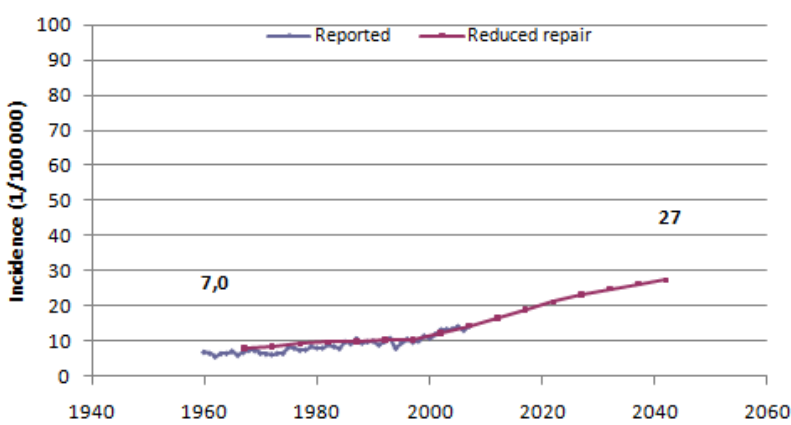

Figure 4a: Norwegian age-adjusted brain tumor incidence rates, 1960-2007 as reported and if DNA repair efficiency is decreased from mobile phone use.

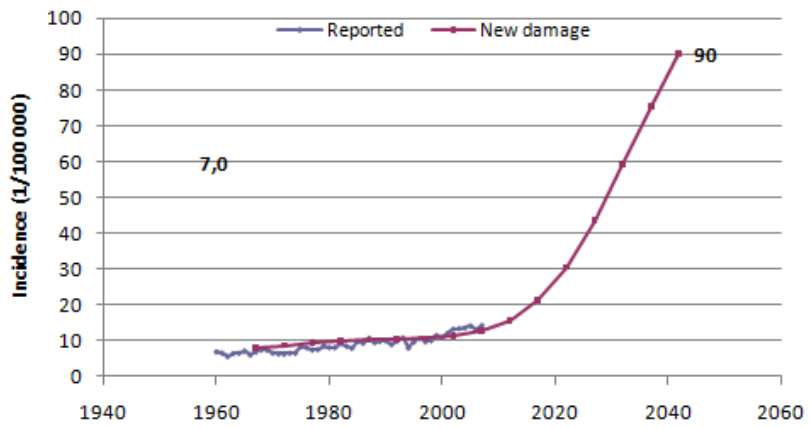

Figure 4b: Calculated development of age-adjusted brain tumor rates in Norway assuming the use of cell phones at the level used in 2006 creates 25 -fold brain damages as earlier by natural causes. A 25 -fold increase in the brain cancer incidence is not expected until 2080 due to latency effects.

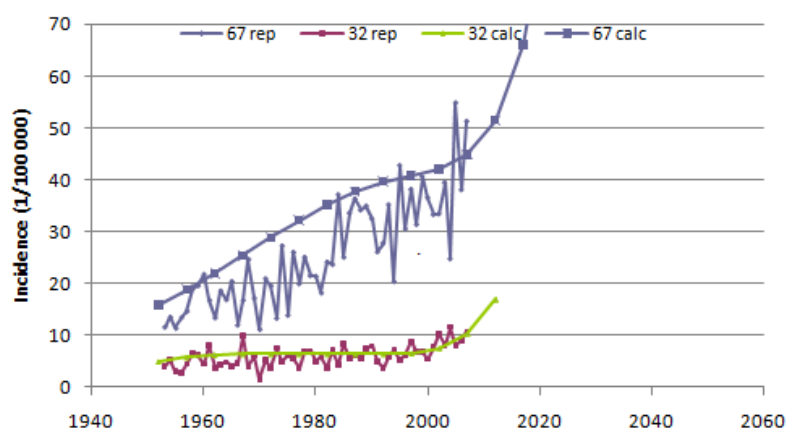

Figure 5: Reported age-adjusted brain tumor incidence rates in Norway 1953-2007 for 65-69 (67) and 30-34 (32) age groups and calculated rates based on increased DNA damage.

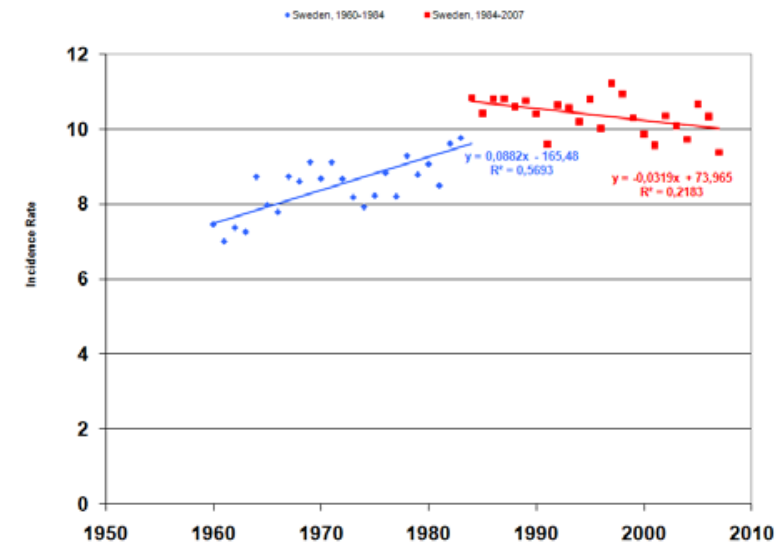

Figure 6: Reported Swedish age-adjusted brain tumor incidence rates, 1960-2007.

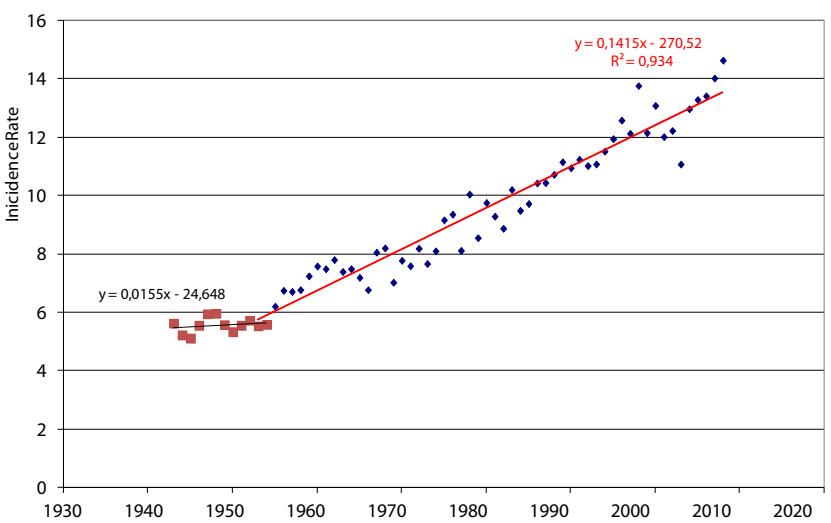

Figure 7: Reported Danish age-adjusted brain tumor incidence rate, 19432007.

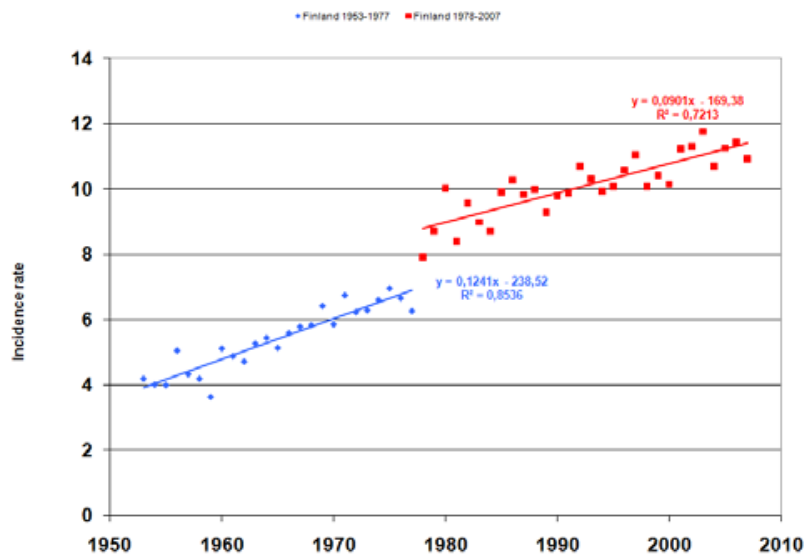

Figure 8: Reported Finish age-adjusted brain tumor incidence rates, 19532007.

Northern parts of Sweden show higher brain cancer rates than in the Stockholm area, suggesting that this increase could be the result of increased cell phone power in rural areas [13].

The USA brain cancer rates increased from 1955-1984, then 


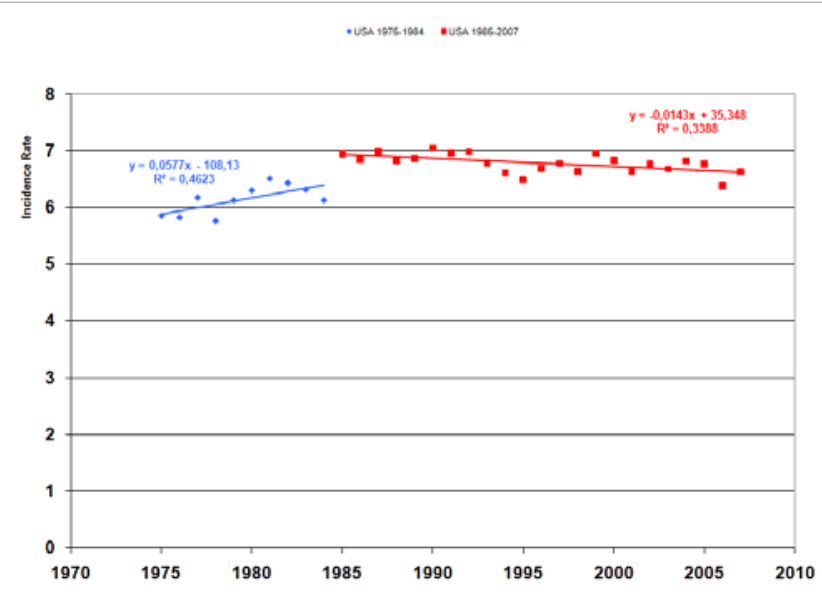

Figure 9: USA Brain Cancer Incidence 1975-2007.

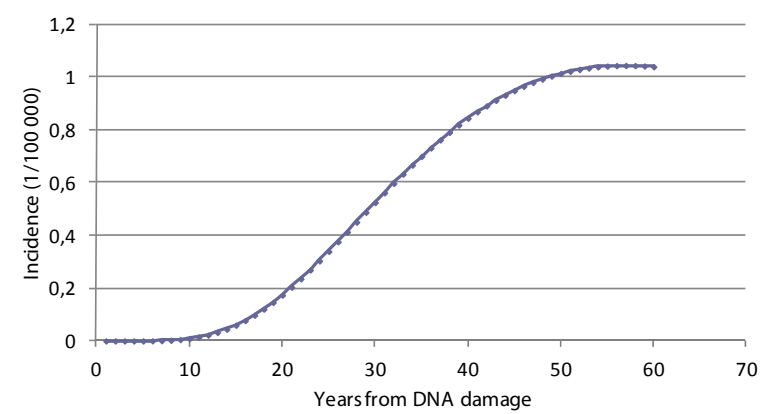

Figure 10: The cancer risk contribution from brain damages acquired during one specific year of life.

decreased from 1985-2007 (see Figure 9). This discontinuity is an artifact of the aging population when the change was made from the 1970 to the 2000 Standard Population. Due to later roll-out and slower adoption of mobile phones in the USA compared with Nordic countries, we should not expect to see increasing rates for another 10 years. In 2000 the prevalence of cell phone subscribers in the United States was $40 \%$ while in the Nordic countries it was $70 \%$ [22].

\section{Discussion}

The time trends presented here point at differences between countries or between different areas within a country. It is well known that the output power from mobile phone handsets depends on the closeness to base stations. In a city region the output power may be only a few $\mathrm{mW}$ while in a rural area long away from the nearest base station the output power automatically switches to the maximum level, e.g. $2 \mathrm{~W}$ or almost 1000 times higher than in the city region. The difference between median power output in rural compared to urban areas is $17-18$ fold in daytime and is 13 -fold in the night-time. In rural areas, the output power is at its maximum $50 \%$ of the time where in the city it is $25 \%$ of the time [13]. The Swedish team led by Dr. Lennart Hardell found that rural digital cell phone users had a much higher risk of brain cancer (8.4-fold) than urban users (1.4-fold) [23]. It should be noted that this and similar studies show associations but do not prove causation.

Studies by Hallberg and Johansson [24] have shown a strong correlation between output power and health. More specifically, it was shown by Hallberg $[25,26]$ that over the last 2 decades, in rural areas where the median output power from mobile handsets is highest also has the largest increases in brain tumour incidence and hearing problems.

The big change in brain tumor diagnoses was MRI scans, which began in the early 1980s and were ubiquitous by the mid-1990s. CAT scan use has similar time frames. However, MRI scans have better resolution and so could diagnose some tumors not detected by CAT scans. The effect of such new diagnostic techniques would be to find tumors earlier, which would somewhat raise incidence rates in those early years of improved diagnostic tools. But in the following years the incidence would return to where it had been previously, almost all brain tumors would have previously been detected once they had grown larger.

Many studies report on the increased risk of brain cancer on the ipsilateral side of the head (tumor on the same side as the mobile phone is used), which is consistent with the fact that only the ipsilateral side of the head is exposed to cell phone radiation and, for adults, the contralateral side in not exposed [27] All case-control studies show a significant increase risk of brain tumors with data for $>10$ years of ipsilateral use. After 10 years of use the risk on the ipsilateral side may be several times higher than the risk of brain cancer without regard to laterality [28]. The studies also report that brain cancer risks on the contralateral side are less than the risk found without regard to laterality.

The latency time from initial brain damage to brain cancer is a very important parameter to consider for the analysis of reported statistics and related projections. A recent study on time trends for brain tumours in Nordic countries used a short follow-up time of 5-10 years which is inadequate to detect an increase in brain tumour incidence [29]. In our study of cancer statistics reported since mid $20^{\text {th }}$ century in several countries, we found that the latency time actually is over 30 years before a strong contribution to the cancer incidence is to be expected. Figure 10 shows the inherent cancer risk from just one year of standard brain damages according to the model used to fit reported data in Norway (Figures $4 \mathrm{~A}, 4 \mathrm{~B} \& 5$ ). The graph gives the cancer risk contribution from just those brain damages acquired during one specific year in life as a function of coming years. It shows that the main cancer risk contribution is not to be expected until after 30 years since the damage occurred.

Since we have found that recent brain cancer incidence varies between countries, possibly due to differences in average output power from mobile phones, it is more informative to present data per country rather than lumping all data together, as done in recent study on time trends for brain tumours in Nordic countries [29]. Furthermore, it is important to present all data that is available and not arbitrarily cut the trend line year 2003 when 4 additional years of data were available.

Modelling cancer rates has successfully been used earlier to understand time trends in skin melanoma incidence [17] and mortality due to Alzheimer's disease [30]. As earlier explained (in the Methods section above) the two parameters of the main cancer risk function were varied to get optimum fit to reported age-adjusted rates over time. In order to calculate the age-standardized rates the computer has to calculate all age-specific rates for all birth cohorts over time. The calculated age-standardized rates are then adjusted to fit reported data by parameter variation. Thus, if the calculated age-specific incidence over time fits well to reported data, it is a strong argument that the 
basic model construction works and can be used for future prediction purpose. Likewise, if a hypothesis is modelled and by parameter variation is made to fit age-adjusted rates still does not fit the reported age-specific data; there is no support for that particular hypothesis. An example of that was given in the melanoma study discussed above [17] where it was shown that increasing sun tanning habits since 1930 to 1980 failed to explain the sudden increase in skin melanoma right after 1955 in the Nordic countries.

Actual brain cancer incidence rates are the retrospective data in Table 3. The limitations of any model, including our model is that many variables are poorly understood, so accurate predictions may not be possible. This does not imply the models are worthless, or that they cannot be enhanced over time.

The brain cancer model indicates that an environmental change had taken place after 1950 for all examined countries. That change had a negative influence on the body's ability to repair DNA brain damage. The effect of reduced DNA repair efficiency is that damage is active for a longer time and thus results in an increased risk of developing cancer. In age-specific time trends the result is an increased incidence that stabilizes at a new level after a number of years for younger cohorts. Older cohorts will need longer times to reach their stabilization level. Examples of such data are given in Figure 5 for brain cancer, or for melanoma as discussed above [17]. Data from Denmark have been reported since 1943 and we can see from Figure 7 how the stable incidence was broken from about 1955 . This is quite in line with the model results that indicated mid $20^{\text {th }}$ century to be a time when the DNA repair efficiency suddenly dropped. Similar trend-breaks around 1955 have been noticed in data from Denmark for breast cancer as well as for melanoma.

It has been shown [18] that the general trend of 'electrification' in the modern society since the beginning of the $20^{\text {th }}$ century may have had some negative effects on public health. Brain cancer seems to be one of those negative effects. This suggests that the increase brain cancer incidence could be the result of the introduction of electricity. Because urban areas were the first to be electrified, any increase would first be seen in urban areas. In 2001 the World Health Organization declared the fields resulting from the use of electricity were a possible human carcinogen [20].

Franzellitti et al. [31] reported in 2010 about how radiation from GSM $1.8 \mathrm{GHz}$ cellphone radiation was able to affect the DNA integrity.

A 2009 report, Cellphones and Brain Tumors: 15 Reasons for Concern [32] reported that industry funding of studies strongly reduces the probability that an effect from exposure to cellphone microwave radiation will be found. This suggests that funding bias is often the reason that published studies of health risks from exposure to electromagnetic fields find no effect.

\section{Conclusions}

It is too early to predict future rates of brain cancer, but these preliminary findings suggest that we should prepare for about a doubled brain cancer incidence rate and possibly as high as 25 times the incidence we have today. One result of such a worldwide increase in brain cancers would be a dramatic shortage of neurosurgeons leading to increased mortality. Any statement about harmless cell phones based on only 5-10 years of use has no scientific basis due to the long latency times involved.
The main conclusions from this study are:

1. Brain and CNS cancer has been increasing in many countries since roughly 1950, possibly due to the introduction of immune disturbing technologies such as electricity.

2. During recent years Norway, and some counties of Sweden show signs of an increase in brain cancer incidence rates while Denmark, Finland and the USA have not shown signs of an accelerating increase. The stability of the USA incidence rates may be due to a later start of cell phone use, combined with a slower increase in prevalence. Also because the USA only began collecting cancer data in 1975 (decades later than the Nordic countries), no information is available if there was an increased brain cancer rate similar to the Nordic countries.

3. Based on reported incidence rates during the $20^{\text {th }}$ century we conclude that the latency time for brain cancer to develop from an initial damage is over 30 years. It is erroneous to make optimistic projections for the future based on cancer statistics covering time spans of only 5 to 10 years.

4. The recent trend breaks we have noticed in Norway and in parts of Sweden may be regarded as a warning. If cell phones are used in rural areas then we can expect to see drastically increasing rates of brain cancer within the next few decades in rural areas.

5. There are many actions that manufacturers can take to minimize cell phone radiation exposures.

- Ericsson and Nokia registered patents in 1997 [33] to limit the maximum output power from cell phones to levels below current values of $2 \mathrm{~W}$ or $1 \mathrm{~W}(900 \mathrm{MHz}, 1800 \mathrm{MHz}$, respectively).

- Antennae can be designed to radiate away from the users instead of current designs which radiate omni-directionally which results in a substantial proportion of the cell phone radiation unnecessarily being absorbed by the head and body.

- The speaker used to place the cell phone against the ear can be replaced by a wired headset thereby removing the need to place a radiating device immediately against the head.

6. There are many actions that individuals can take to minimize cellphone radiation exposures. [32, Appendix 2]

- When on a call, use a wired headset (not a wireless headset such as a Bluetooth), or use in speaker-phone mode, or send text messages. Keep the cell phone away from your body (particularly pant/trouser or shirt pockets) or use a belt holster designed to shield the body from cellphone radiation, when not in use (stand-by mode).

- Avoid use in a moving car, train, bus, or in rural areas at some distance from a cell tower (AKA mast or base station) as any of these uses will increase the power of the cellphone's radiation.

- Use the cellphone like an answering machine. Keep it off until you want to see who has called.

- Use a corded land-line phone, whenever possible, instead of a wireless phone.

- Avoid use inside of buildings, particularly with steel structures. 
Citation: Hallberg Ö, Morgan LL (2011) The Potential Impact of Mobile Phone Use on Trends in Brain and CNS Tumors. J Neurol Neurophysiol S5. doi:10.4172/2155-9562.S5-003

- Do not allow your children to sleep with a cell phone beneath their pillow or at the bedside.

- Do not allow your children to use a cell phone except in emergencies.

\section{References}

1. Hardell L, Carlberg M, Hansson Mild K (2011) Pooled analysis of case-control studies on malignant brain tumours and the use of mobile and cordless phones including living and deceased subject. Int J Oncol 38: 1465-1474.

2. Cardis E, Deltour I, Vrijheid M, Combalot E, Moissonnier M, et al. (2010) Brain tumour risk in relation to mobile telephone use: results of the INTERPHONE international case-control study. Int J Epidemiology 39: 675-694.

3. Hardell L, Carlberg M, Söderqvist F, Hansson Mild K (2008) Meta-analysis of long-term mobile phone use and the association with brain tumours. Int $\mathrm{J}$ of Oncology 32: 1097-1103.

4. Chou CK, D'Andrea J, Peterson R (2006) IEEE Standard for Safety Levels with Respect to Human Exposure to Radio Frequency Electromagnetic Fields, 3 $\mathrm{kHz}$ to $300 \mathrm{GHz}$, Section 1.1 Scope, Revision of IEEE Std C95.1-1991.

5. Nittby $H$, Brun A, Eberhardt J, Malmgrend L, Persson BRR, et al. (2009) Increased blood-brain barrier permeability in mammalian brain 7 days after exposure to the radiation from a GSM-900 mobile phone. Pathophysiology 16 : 103-112.

6. Fejes I, Závaczki Z, Szöllosi J, Koloszár S, Daru J, et al. (2005) Is there a relationship between cell phone use and semen quality. Arch Androl 51: 385393.

7. Agarwal A, Deepinder F, Sharma RK, Ranga G, Li J (2008) Effect of cell phone usage on semen analysis in men attending infertility clinic: an observational study. Fertil Steril 89: 124-128.

8. Makker K, Varghese A, DesaiNR, Mouradi R, Agarwal A (2009) Cell phones: modern man's nemesis? Reprod Biomed Online 18: 148-157.

9. Phillips JL, Singh NP, Lai H (2009) Electromagnetic fields and DNA damage. Pathophysiology 16: 79-88.

10. Weisbrot D, Lin H, Ye L, Blank M, Goodman R (2003) Effects of Mobile Phone Radiation on Reproduction and Development in Drosophila melanogaster. J Cell Biochem 89: 48-55.

11. Hardell L, Carlberg M, Hansson Mild K (2006) Pooled analysis of two casecontrol studies on the use of cellular and cordless telephones and the risk of benign brain tumours diagnosed during 1997-2003. Int J Oncol 28: 509-518.

12. Hardell L, Carlberg M, Hansson Mild K (2006) Pooled analysis of two casecontrol studies on use of cellular and cordless telephones and the risk for malignant brain tumours diagnosed in 1997-2003. Int Arch Occup Environ Health 79: 630-639.

13. Lönn S, Forssén U, Veccia P, Ahlbom A, Feychting M (2004) Output power levels from mobile phones in different geographical areas; implications for exposure assessment. Occup Environ Med 61: 769-772.

14. Hardell L, Carlberg M, Hansson Mild K (2005) Use of cellular telephones and brain tumour risk in urban and rural areas. Occup Environ Med 62: 390-394.

15. Sadetzki S, Chetrit A, Jarus-Hakak A, Cardis E, Deutch Y, et al (2007) Cellular Phone Use and Risk of Benign and Malignant Parotid Gland Tumors-A Nationwide Case-Control Study. Am J Epidemiol 167: 457-467.

16. Stang A, Anastassiou G, Ahrens W, Bromen K, Bornfeld N, et al. (2001) The possible role of radiofrequency radiation in the development of uveal melanoma. Epidemiology 12: 7-12.

17. Hallberg Ö (2008) A reduced repair efficiency can explain increasing melanoma rates. Eur J Cancer Prev 17: 147-152.

18. Milham S (2010) Historical evidence that electrification caused the 20th century

This article was originally published in a special issue, Brain Tumor handled by Editor(s). Dr. Colleen Dockstader, The Hospital for Sick Children, Canada epidemic of "diseases of civilization". Med Hypotheses 74: 337-345.

19. IARC Monographs on the Evaluation of Carcinogenic Risks to Humans (2002) Non-lonizing Radiation, Part 1: Static and Extremely Low-Frequency (ELF) Electric and Magnetic Fields. IARC Monogr Eval Carcinog Risks Hum 80: $1-305$.

20. CBTRUS (2011) CBTRUS Statistical Report: Primary Brain and Centra Nervous System Tumors Diagnosed in the United States in 2004-2007.

21. Sadetzki S, Cherit A, Freeman L, Stoval M. Modan B, et al. (2005) Long-Term Follow-up for Brain Tumor Development after Childhood Exposure to lonizing Radiation for Tinea Capitis. Radiat Res 163: 424-432.

22. Telecommunication markets in the Nordic countries (2010) Post and Telegraph Administration, Sweden.

23. Hardell L, Carlberg M (2009) Mobile phones, cordless phones and the risk for brain tumors. Int $\mathrm{J}$ of Oncology 35: 5-17.

24. Hallberg Ö, Johansson O (2004) Mobile handset power and health Electromagnetic Biology and Medicine 23: 229-239.

25. Hallberg Ö (2007) Increasing incidence of brain tumors in sparsely populated areas. Pathophysiology 14: 121-122.

26. Hallberg Ö (2005) Hearing problems and acoustic neuroma cancer in Sweden. Pathophysiology 12: 143-144.

27. Cardis E, Deltour I, Mann S, Moissonnier M, Taki M, et al. (2008) Distribution of RF energy emitted by mobile phones in anatomical structures of the brain. Phys Med Biol 53: 2771-2783.

28. Morgan LL (2009) Estimating the risk of brain tumors from cellphone use: Published case-control studies. Pathophysiology 16: 137-147.

29. Deltour I, Johansen C, Auvinen A, Feychting M, Klaeboe L, et al. (2009) Time Trends in Brain Tumor Incidence Rates in Denmark, Finland, Norway, and Sweden, 1974 - 2003. J Natl Cancer Inst 101: 1721-1724.

30. Hallberg Ö (2009) Is increased mortality from Alzheimer's disease in Sweden a reflection of better diagnostics? Curr Alzheimer Res 6: 471-475.

31. Franzellitti S, Valbonesi $P$, Ciancaglini N, Biondi C, Contin A, et al. (2009) Transient DNA damage induced by high-frequency electromagnetic fields (GSM $1.8 \mathrm{GHz}$ ) in the human trophoblast HTR-8/SVneo cell line evaluated with the alkaline comet assay. Mutat Res 683: 35-42.

32. http://www.radiationresearch.org/pdfs/reasons_us.pdf

33. http://mobilstopp.nu/Uncover/Papers/HIR/HIR05_2.pdf 